\title{
Diagnostic Evaluation of Public Transportation Mode Choice in Addis Ababa
}

\author{
Mintesnot Gebeyehu and Shin-ei Takano \\ Hokkaido University, Sapporo, Japan
}

\begin{abstract}
The major modes of public transportation in the city of Addis Ababa are buses and taxis. There is no rail transit within the city. The existing public transportation is of a low quality because of the limited number of buses and taxis, poor management, and bad behavior of drivers. Despite these prevailing problems, efforts to make an empirical study of the city's urban transportation are insignificant. This research attempts to develop an ordered logit model to examine citizens' perceptions of the bus condition, as a determining factor for their choice of bus transportation, and to develop a binary logit model to analyze traveler choice behavior. A diagnostic analysis is undertaken based on the two models. The result shows that citizens' perceptions of the three chosen bus condition aspects (fare, convenience, and frequency) have a significant influence on public transport mode choice.
\end{abstract}

\section{Introduction}

Mobility in the developing world is often characterized by travel demand that far exceeds supply (Darido 2003). The city of Addis Ababa is not an exception to this reality. Demand for urban public transport services is growing in the same way as in other third-world cities (Jacobs et al. 1986). Public transportation is an important element in day-to-day activities in Addis Ababa because (1) it is a relatively 
affordable means of transportation, (2) infrastructure is not sufficient to promote private vehicle ownership, and (3) it promotes reduction of environmental pollution and traffic accidents. Even though the role of public transportation is noteworthy, the service provision is not good enough as the demand is much greater than the supply. As the population and the number of passengers increase, service should be expected to grow. This is not practically true in the city because of financial and managerial constraints. Despite prevailing problems, efforts to make an empirical study of the transportation in the city are insignificant.

Several analytical methods have been developed to examine the mode choice behavior of travelers. The influence of socioeconomic issues and mode-related variables are examined using discrete choice analysis. Traveler modal choice is generally explained by three basic factors: characteristics of the journey (e.g., length, time of day, and purpose), the socioeconomic characteristics of the traveler, and the transport system (Thamizh Arasan et al. 1996). Other literature identifies added characteristics of the trip itself, land use and urban design (Racca and Ratledge 2004). The most common methods of mode choice analysis are binary and multinomial logit models (Ghareib 1996; Mintesnot and Takano 2005a; Yamamoto et al. 2000; Thamizh Arasan et al. 1996). No literature documents the application of ordered models for mode choice as choice does not lend itself to ranking responses. It is choosing one mode over the other. Other issues like seat belt usage and injury analysis are analyzed using an ordered logit model for the dependent variables of ranking response (Hamad and Easa 1998; Wang and Kockelman 2005). However, travelers' mode choice is not only dependent on their socioeconomic backgrounds. Their perception of the mode also plays a significant role in affecting their choice. Because the public transportation alternatives in Addis Ababa are limited to only two modes, making perception analysis is essential in addition to the widely used mode choice model. Perception responses have ranking nature, so they could be analyzed using ordinal models. Using perception analysis, this study attempts to provide an improved modeling of the mode choice. Unlike previous studies on mode choice, this study uses the ordered logit model with four ordered levels of perceptions on three mode-related aspects (fare, convenience, and frequency); the result is then be used as an input for the mode choice model.

\section{Methodology and Objectives}

The research approach implemented in this study involved data collection, analysis of bus company data, and modeling travelers' perception on bus transportation 
and its influence on public transport mode choice using logit models. A survey was undertaken in September 2004 to understand better the respondents' attitudes on bus service. The study's objective is to analyze the public transport modal choice behavior of residents and their perception on bus condition parameters as a determining factor in their bus choice. In this study an ordered logit model is developed to examine citizens' perceptions on bus conditions, in addition to the widely used binary logit model, which is developed for public transport mode choice analysis.

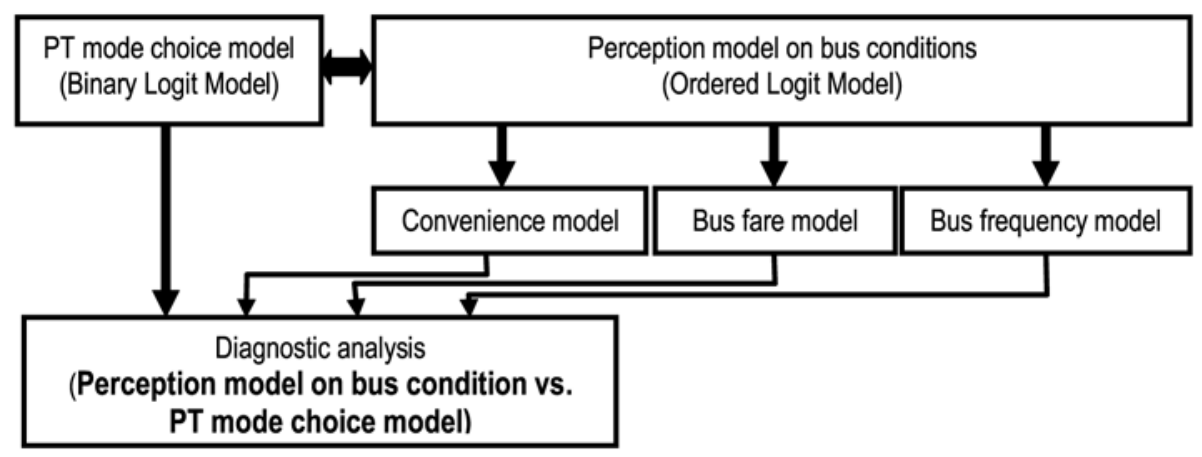

\section{Figure 1. Framework of the Proposed Models}

\section{Background}

Addis Ababa, the capital city of the Federal Democratic Republic of Ethiopia, is located in the center of the country. Established in 1886, the city has experienced several planning changes that have influenced its physical and social growth. The area of Addis Ababa is 530.14 square kilometers. Its current population is about 2.57 million (2005 estimate), about 3.9 percent of the population of Ethiopia. It also represents about 26 percent of the urban population of Ethiopia. Addis Ababa has an aggregate population density of 4,847.8 persons per square kilometer. Public transport in the city consists of conventional bus services provided by the publicly owned Anbessa City Bus Enterprise, taxis operated by the private sector, and buses used exclusively for the employees of large government and private companies. The role of bicycles in urban transport is insignificant (World Bank African Region Scoping Study 2002). The road network of Addis Ababa is limited in extent and right of way. Its capacity is low, on-street parking is prevalent, and 
the pavement condition is deteriorating. Despite a large volume of pedestrians, there are no walkways over a large length (63\%) of the roadway network. This is a major concern because it contributes to the increased pedestrian involvement in traffic accidents (10,189 accidents occurred in 2004 [Ethiopian Roads Authority 2005]).

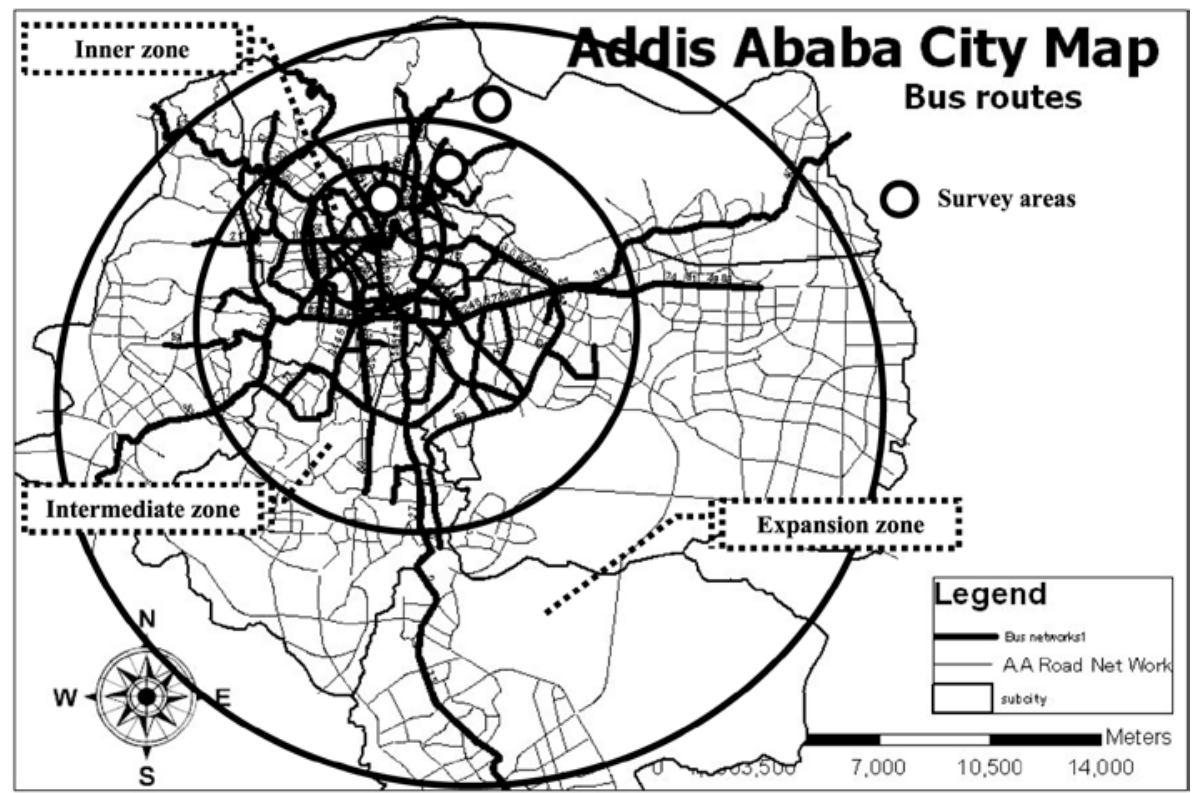

Figure 2. City of Addis Ababa

\section{Overview of Public Transportation}

In the city of Addis Ababa, the dominant public transportation modes are city buses and taxis. Although buses have 30 seats each, they have a carrying capacity of 100 people in a crowded situation. Taxis have a carrying capacity from four (small taxis) to 12 persons (large taxis). There is no rail transit within the city. Car ownership among residents is very low, so the majority depend on buses and taxis for their day-to-day mobility. Walking is the main means of transportation for a number of residents. Unlike other cities in the country, bicycle use is insignificant because of topographic inconveniences. 
Buses provide 40 percent of the public transport in the city; taxis account for 60 percent (Ethiopian Roads Authority 2005). The city is currently experiencing horizontal growth, but the bus service has not exhibited growth proportionate enough to accommodate this increase. Analysis results of the transit availability indices show that only the city center is being served by the existing bus networks while urban expansion areas have low transit availability (Mintesnot and Takano 2006). Taxis experience many operating constraints, including bad driver behavior, excessive fares, and high accident rates. This study examines the existing situation as an input for future public transport development and improvement programs.

\section{Buses}

Only one bus company, Anbessa City Bus Enterprise, operates in the city. The company is mandated to provide public transport services to the city and the surrounding areas. It operates a fleet of 524 conventional buses, with an average vehicle age of six years, and provides scheduled services along 93 routes as well as nonstop rapid (express) services. An additional 0.1 Ethiopian birr per trip (1USD $=8.8$ Ethiopian birr) is charged for express services. The basic bus service has a system of flat fares for the route with a range varying according to distance. There are about 1400 bus stops, 16 service check stations, and 3 main bus terminals. The Anbessa City Bus Enterprise, which is subsidized by the city council, moves around 40 percent of all public transport passengers. The absence of an up-to-date structure in the bus company, shortage of finance, and reduction of the subsidy from the government are the biggest challenges for the service. The lack of welldefined performance parameters to evaluate the operational efficiency of the bus company is also a constraint for development. The prospects are the year-to-year increase in the number of bus users (Anbessa City Bus Enterprise 2004; Mintesnot and Takano 2005b; SEMALY Public Transport Consultants 2001). Spatial analysis of the bus network coverage shows that only the city center, which is where commercial activities are abundant, boasts high bus network availability. Areas with low or no bus network availability are in localities where the city is exhibiting trends in urban expansion and where residential developments are underway. According to the recent structural synthesis map, prepared by the Addis Ababa Master Plan Revision Office, those sections are strategic areas for city expansion development (Office of the Revision of Addis Ababa Master Plan 2002). 


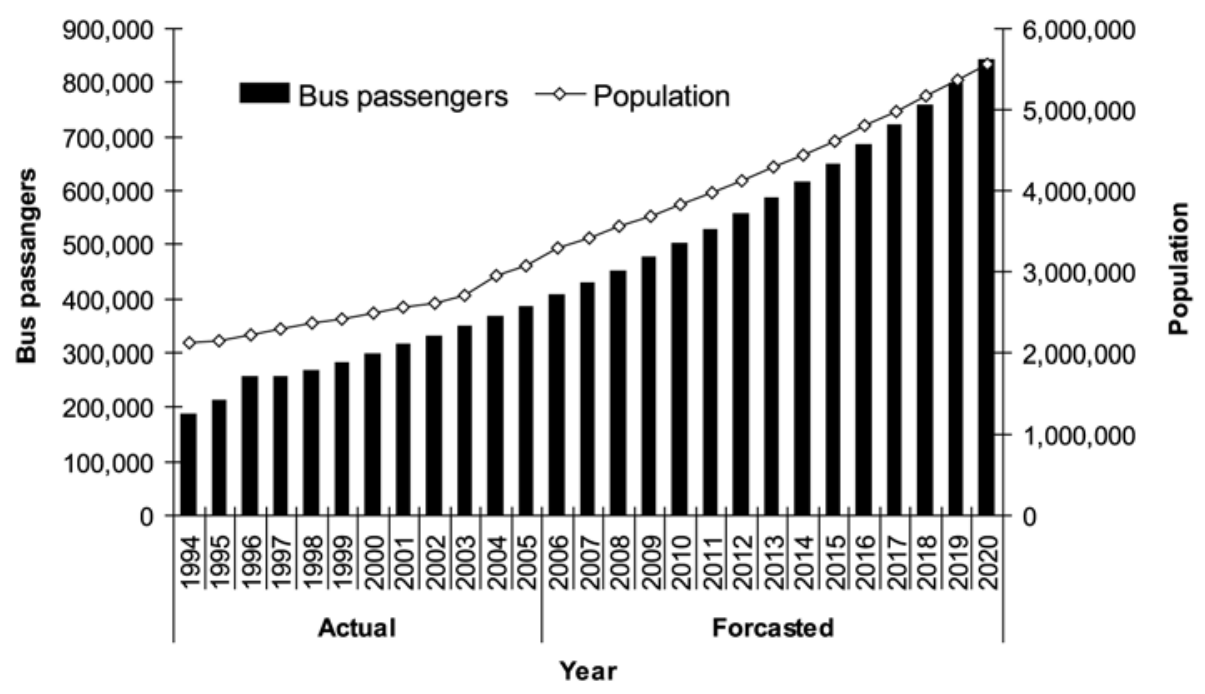

Source: The Bus Company and Central Statistics Authority.

\section{Figure 3. Population and Bus Passenger Growth}

\section{Taxis}

Of the 14,083 taxis operating in Addis Ababa in 2005, 12,283 had 12 seats and 1,800 were small taxis with 4 seats. Of the total number of taxis, only 11,806 were inspected and registered by the Addis Ababa Transport Authority through March 2005. Public transport service is highly dependant on taxis as a mode despite high fares (taxis are an expensive means of transportation when compared to buses), which are not affordable, particularly for the low-income group (i.e., the urban poor). Taxis, which are operated by the private sector, usually run on fixed routes even if they are not highly enforced by the government (unlike that of the bus). Taxi speeds are affected by frequent stopping for loading and unloading. Some unpublished documents reveal that, when compared, the carrying capacity of taxis to city buses is eight to nine times less. Inadequate vehicles, loading extra passengers, and bad behavior of taxi drivers and their assistants make taxi transport difficult. 
Table 1. Registered and Inspected Taxis for 1999-2005

\begin{tabular}{lcc} 
Year & Registered Taxis & Growth Rate (\%) \\
\hline $1999-2000$ & 8266 & - \\
$2000-2001$ & 8847 & 7.0 \\
$2001-2002$ & 9910 & 12.0 \\
$2002-2003$ & 9930 & 0.2 \\
$2003-2004$ & 9262 & -6.7 \\
$2004-2005$ & 11806 & 27.5 \\
Average & 8.0 & \\
\hline
\end{tabular}

Source: Addis Ababa Transport Authority, 2005.

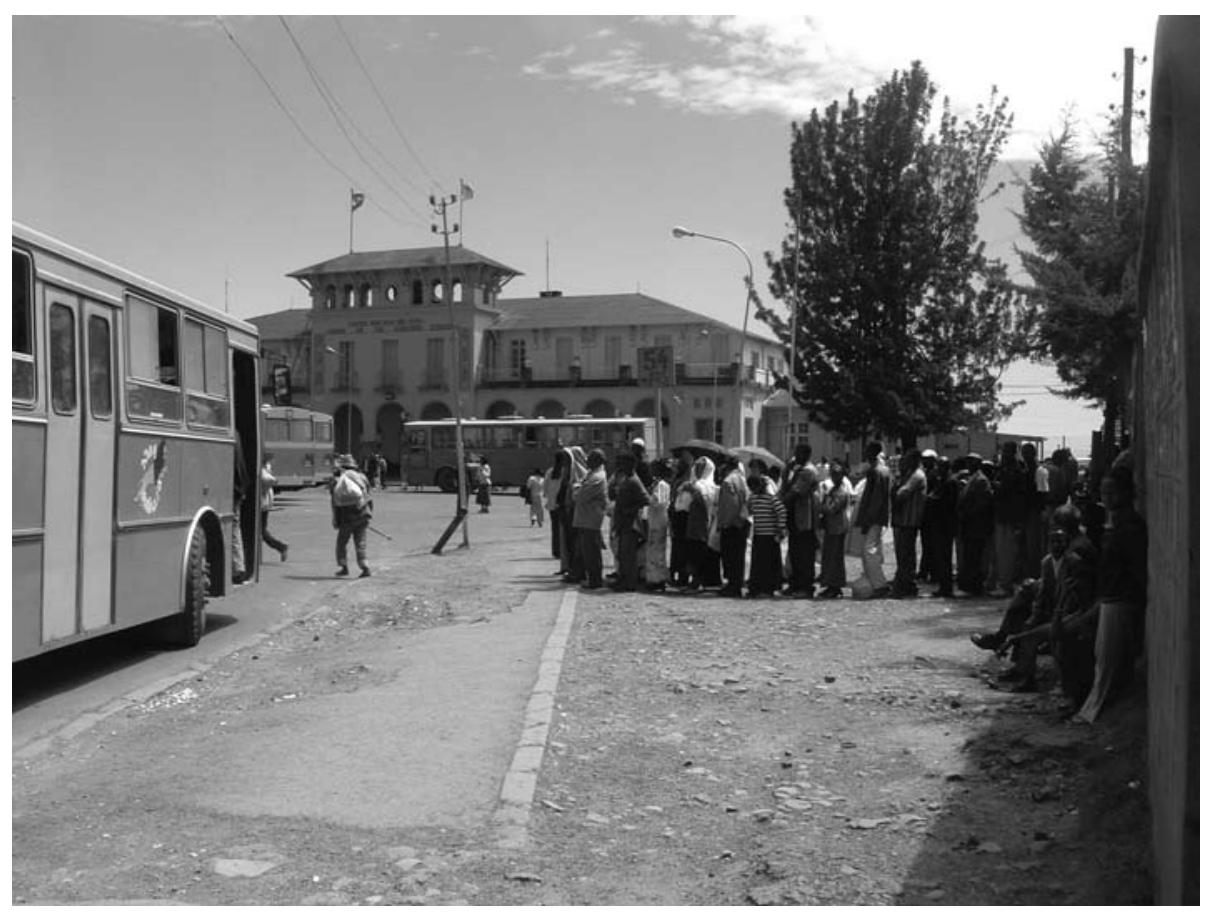

Figure 4. Buses in Addis Ababa 


\section{Figure 5. Taxis in Addis Ababa}

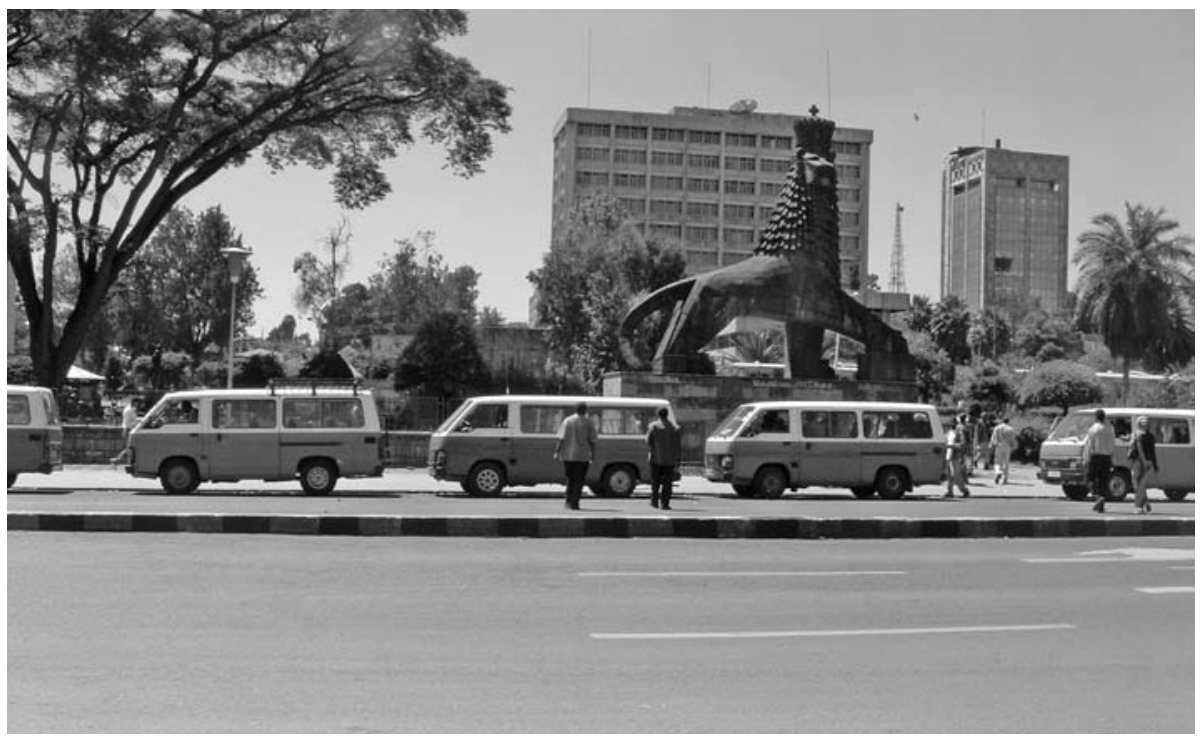

\section{Data Description}

\section{Socioeconomic Characteristics of Respondents}

To determine the city's public transportation condition and the effectiveness of implementing the proposed models, a sample survey of residents was undertaken in September 2004. The survey questionnaire addressed socioeconomic variables, demographic characteristics, travel patterns, mode attributes, satisfaction variables, and bus condition data. A door-to-door survey of 750 respondents from three categories of society (innercity residents, those living in intermediate zones, and expansion area [periphery] residents) was performed. Innercity residents are those living in and around the central business districts; periphery residents are those living in the expansion urban edges; and intermediate residents are those living in the middle of the two mentioned locations.

According to the general analysis results of the survey, 64 percent of the respondents use bus as their typical mode of transportation, 18 percent use taxis as their major mode of transportation, and 12 percent walk. The remaining respondents preferred other modes of transportation like private car. The bicycle is not considered a mode of transportation in the city due to inconvenient topography. The 
Ethiopian Road Authority in 2005 stated that walking enjoys the largest share of overall trips, if all short-distance trips are included. As to the socioeconomic and demographic characteristics of the respondents, 58 percent are male and 42 percent are female. Their income varies from low (below 100 Ethiopian birr) to high (above 2000 Ethiopian birr). However, the majority have an income within the range of 100 to 300 Ethiopian birr. Thus, the majority of the respondents are in the low-income group. In terms of jobs, 35 percent of the respondents are public company employees and 19 percent are private company employees. In addition, 24 percent run their own small businesses, 8 percent are students, and the remaining 14 percent are unemployed. More than 90 percent of the respondents do not own a car and/or have a driver's license. Family size ranges from 1 to 11, with average household size being 5.08. Work is the main purpose for trips, followed by educational activities. The zonal variation study on mode choice showed that periphery area residents are more dependent on bus transportation than inner and intermediate zone residents. Innercity residents are the dominant taxi users.

\section{Attitudinal Data on Public Transport Conditions}

The survey addressed three bus condition parameters-bus fare, bus convenience (boarding, in-bus crowd, bus steps and chair convenience etc.), and bus frequency. The majority of those surveyed responded that bus is less costly when compared with other modes of transportation. Of 733 respondents, 44 percent replied that bus is strongly preferable, 47 percent said preferable, 7 percent and 2 percent said it is less preferable and nonpreferable, respectively, where fare is concerned. In terms of convenience, most respondents said bus is not convenient, or it is less convenient, when compared with other modes of transportation. Very few respondents noted that bus is a convenient mode of transportation in the city. A high number of respondents reported that bus frequency is good, even though a significant number of respondents said the bus has low and very low frequency. Only a few answered that bus has very high frequency (see Figure 7). Taxi is a less preferable mode of transportation when fare is considered. Taxis are an expensive mode of transport in the city, and are not affordable for the urban poor who account for the majority of the population. The respondents, however, believe that taxi is preferable in terms of convenience because there is no considerable intaxi crowd when compared with buses. Concerning frequency/delay parameters, taxis function better than buses as they have frequent services, which is attributed to the competition among taxi drivers to increase daily revenue despite the effect of loading and unloading on the speed of the journey. 


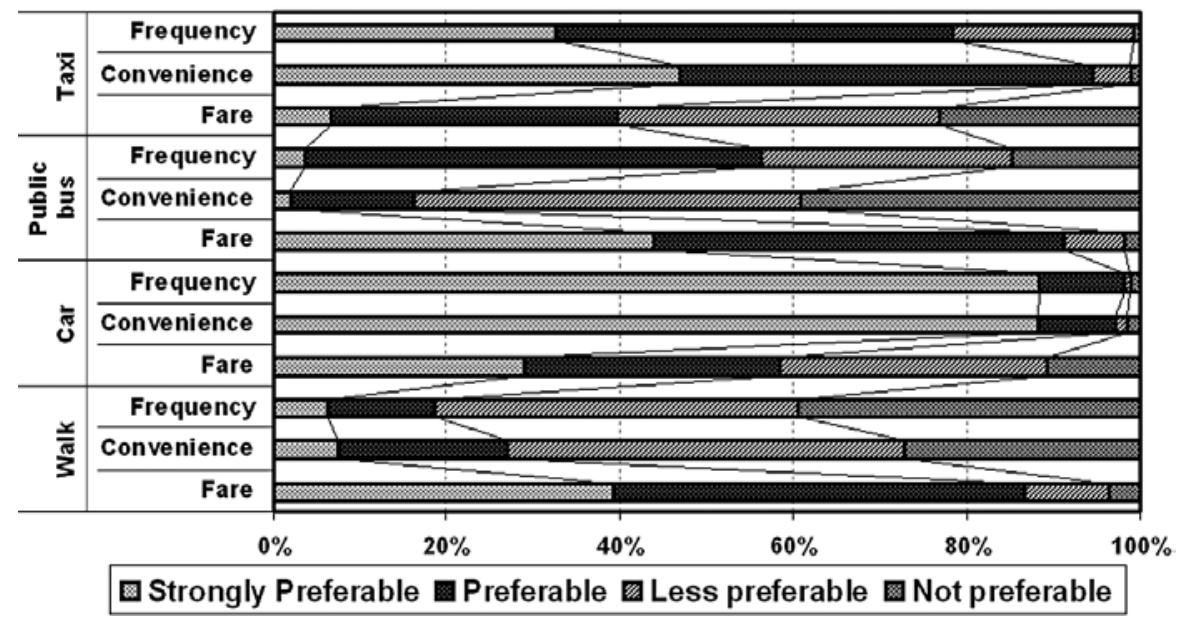

\section{Figure 6. Attitude Toward Different Modes}

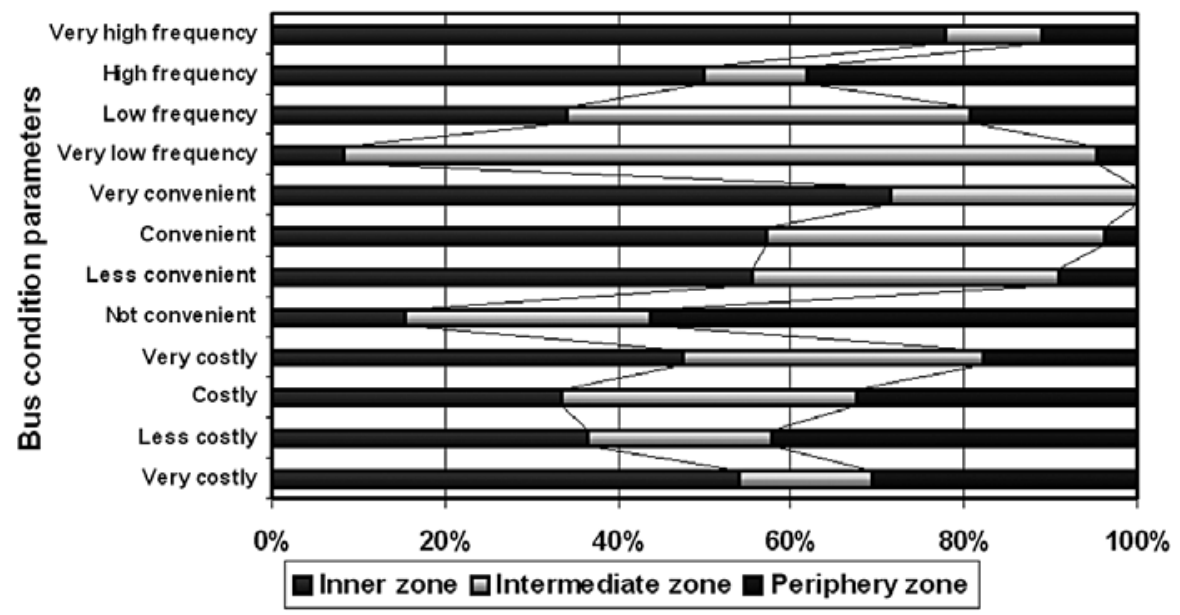

Figure 7. Attitude Toward Bus Service 


\section{Model Structure}

Two models were formulated in this study: an ordered logit model and a binary logit model. The ordered logit model is used to examine the influencing factors affecting citizens' perceptions on bus service conditions, and, in turn, affecting choice of mode. The binary logit model is used to estimate the likelihood of the public transportation mode choice with the dependent variable being the public transportation mode, which gets 1 if the mode is bus and 0 if it is taxi. The two models are discussed in more detail below.

\section{Citizens' Perceptions Model on Bus Conditions: Ordered Logit Model}

Some multinomial choice variables are inherently ordered. Although the outcome is discrete, the multinomial logit or probit models would fail to account for the ordinal nature of the dependent variable (Green 2000). An ordered logit model is able to treat variables with a ranking order. Modeling citizens' perceptions on current bus conditions is based on the ranked responses of a survey with three parameters (bus fare, bus convenience, and bus frequency). Suppose that the values of $Y$ represent an ordering of items. For example, let $Y_{i}$ be the outcome of a bus condition test of observation $i$ for the three evaluation parameters, coded like

$$
Y_{i}=\left\{\begin{array}{l}
0: \text { very costly/not convenient/very low bus frequency } \\
1: \text { costly/less convenient/low bus frequency } \\
2: \text { less costly/convenient/high bus frequency } \\
3: \text { not costly/very convenient/very high bus frequency }
\end{array}\right.
$$

$Y$ is not a quantity but a ranking, nevertheless a larger value of $Y$ means more, or better. In this case there exists a known natural number $m$ such that

$$
P\left[Y_{i} \in\{0,1,2 \ldots m\}\right]=1
$$

This type of data is usually modeled via a latent (unobserved) variable model:

$$
Y^{*}{ }_{i}=\alpha+\beta_{i}{ }^{\prime} X_{i}+\varepsilon
$$

Where:

$Y^{*} \quad$ equals a latent (unobserved) measure of bus condition faced by the respondent 
$X \quad$ is a vector of explanatory variables describing the age, sex, and bus waiting time etc.

$\alpha, \beta^{\prime} \quad$ represents a vector of parameters to be estimated

$\varepsilon \quad$ denotes a random error term (assumed to follow a standard normal dis tribution for probit model or logistic distribution for logit model). In this study, the logistic distribution is followed.

The observed and coded discrete bus condition variable, $\mathrm{Y}_{i}$ is determined from the model as follows (e.g., for the bus fare model):

$$
Y i=\left\{\begin{array}{l}
0 \rightarrow \text { Very costly if } Y_{i}^{*} \leq 0 \\
1 \rightarrow \text { Costly if } 0<Y_{i}^{*} \leq \mu_{1} \\
2 \rightarrow \text { Less } \cos \text { tly if } \mu_{1}<Y_{i}^{*} \leq \mu_{2} \\
3 \rightarrow \text { Not } \cos \text { tly if } Y_{i}^{*}>\mu_{2}
\end{array}\right\}
$$

Where:

$\mu_{\mathrm{i}} \quad$ represent thresholds to be estimated along with the parameter vector $\beta$

The following figure illustrates the correspondence between the latent (unobserved) and coded (observed) bus condition variable:

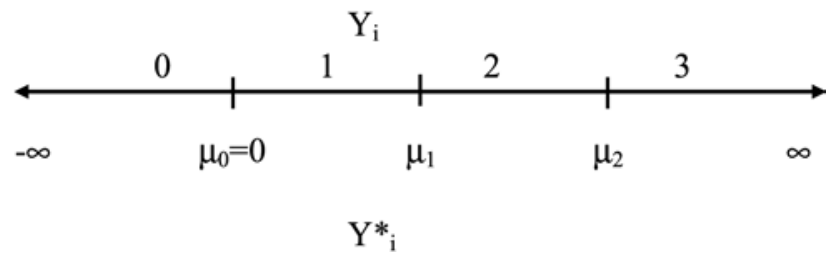

The probability associated with the coded responses of an ordered probability model is as follows:

$$
\operatorname{Pr}\left(Y_{i}=j\right)=\operatorname{Pr}\left(\mu_{j-1}<Y^{*}{ }_{i} \leq \mu_{i}\right)=\operatorname{Pr}\left(\mu_{j-1}<\left[\alpha+\beta_{i}{ }^{\prime} X_{i}+\varepsilon\right] \leq \mu_{i}\right)
$$

As the random error $\varepsilon$ should be distributed, the function will be

$$
\operatorname{Pr}\left(Y_{i}=j\right)=\operatorname{Pr}\left(\mu_{i-1}<Y^{*}{ }_{i} \leq \mu_{j}\right)=F\left(\mu_{i}-\alpha-\beta_{i}{ }^{\prime} X_{i}\right)-F\left(\mu_{j-I^{-}} \alpha-\beta_{i}{ }^{\prime} X_{i}\right)
$$


In ordered logit, $\mathrm{F}(\mathrm{x})$ is specified as the logistic distribution function, i.e.

$$
F(x)=\exp (x) /[1+\exp (x)]
$$

\section{Public Transport Mode Choice Model: Binary Logit Model}

Choice models are widely used in economic, marketing, transportation, and other fields to represent the choice of one among a set of mutually exclusive alternatives. Several models have been developed to analyze transportation choice behavior, which is the key aspect of the demand analysis. This study aimed to model the mode choice behavior of public transport users using the binomial logit model. When travelers are faced with two dominant alternatives, the situation will be termed as a binary choice case. The derivation of any binary choice model is conceptually straightforward, in that the probability of alternative $i$ being chosen can be easily solved.

Consequently, the probability that $j$ is chosen is equal to $[1-P(i)]$. The general form of the binomial logit model is

$$
\operatorname{Prob}\left[Y_{i}=1 \mid b u s\right]=\operatorname{Exp}\left(\alpha+\Sigma \beta_{i} x_{i}\right) /\left[1+\operatorname{Exp}\left(\alpha+\Sigma \beta_{i} x_{i}\right)\right]
$$

The model application is based on the utility theory, which assumes that the decision-maker's preference for an alternative is captured by a value called utility (U). The decision-maker selects the alternative in the choice set with the highest utility

$$
U\left(\text { alternative 1) }=\beta_{I} x_{1}\right.
$$

Where:

$\beta_{1} \quad$ is the coefficient associated with the alternative

$\mathrm{x}_{1} \quad$ is the variables value

$\alpha \quad$ is the constant estimated by the model (Green 1998)

This model is developed in this study to analyze the mode choice behavior of public transportation users. 


\section{Empirical Analyses}

\section{Dependent and Independent Variable Design}

For the ordered logit model, the dependent variable is taken as ranking responses on bus condition parameters. The independent variables keep heterogeneity by comprising the socioeconomic attributes and the attributes related to the mode. As stated earlier, the dependent variable for the binary logit model is the mode of public transportation chosen by the respondents. The major modes of public transportation are bus and taxi. Walking is excluded as the respondents are not using it for long trips. As a binomial logit model has the best output, the data is organized in such a way that the probability of bus choice over taxi is made. The probability estimate of the ordered logit model is also included among the independent variables for the mode choice model. The descriptive analysis of the independent values is given in Table 2 .

Table 2. Descriptive Statistics:

Dependent and Independent Variables for the Two Models

\begin{tabular}{|l|r|r|r|r|l|l|}
\hline Variable & \multicolumn{1}{|c|}{ Mean } & \multicolumn{1}{c|}{ Std. Dev } & \multicolumn{1}{c|}{ Min. } & \multicolumn{1}{c|}{ Max. } & \multicolumn{1}{c|}{ Unit } & \multicolumn{1}{c|}{$\boldsymbol{N}$} \\
\hline Mode: 1 if bus and 0 taxi & 0.788 & 0.409 & 0 & 1 & Binary & 674 \\
\hline Bus condition in terms of fare $(0,1,2,3)$ & 2.332 & 0.687 & 0 & 3 & Ordered & 674 \\
\hline Bus condition in terms of convenience $(0,1,2,3)$ & 0.752 & 0.741 & 0 & 3 & Ordered & 674 \\
\hline Bus condition in terms of bus frequency $(0,1,2,3)$ & 1.436 & 0.784 & 0 & 3 & Ordered & 674 \\
\hline Zone: 0 if inner, 1 if intermediate, 2 if peripheral & 0.923 & 0.803 & 0 & 2 & Ordered & 674 \\
\hline Age & 40.864 & 14.491 & 15 & 85 & Continuous & 674 \\
\hline Sex: 1 if male, 0 if female & 0.568 & 0.496 & 0 & 1 & Binary & 674 \\
\hline $\begin{array}{l}\text { Occupation: } 1 \text { if public and private employee and } \\
\text { student; 0 otherwise }\end{array}$ & 0.605 & 0.489 & 0 & 1 & Binary & 674 \\
\hline Monthly income & 488.72 & 374.751 & 60 & 3140 & ETH. BIRR & 674 \\
\hline Family size & 5.064 & 1.885 & 1 & 11 & Continuous & 674 \\
\hline $\begin{array}{l}\text { Trip purpose: } 1 \text { if work, education, and business; } \\
\text { 0 otherwise }\end{array}$ & 0.780 & 0.414 & 0 & 1 & Binary & 674 \\
\hline Travel time & 45.967 & 21.760 & 4 & 180 & Continuous & 674 \\
\hline Waiting time & 26.169 & 15.880 & 3 & 120 & Continuous & 674 \\
\hline $\begin{array}{l}\text { Fare (differential of taxi and bus fares for the } \\
\text { specified distance) }\end{array}$ & 74.169 & 25.045 & 35 & 125 & ETH Cents ${ }^{2}$ & 674 \\
\hline No. of bus connections & 2.613 & 1.075 & 1 & 6 & Continuous & 674 \\
\hline
\end{tabular}

\footnotetext{
$11 \mathrm{USD}=8.8 \mathrm{ETH}$ birr

21 ETH birr $=100$ ETH cents
} 


\section{Modeling Results: Ordered Logit Model}

The perception model on bus condition is estimated based on three aspects of the existing bus condition as discussed below.

\section{Bus Fare Model}

Results of the bus fare model showed that all the selected parameters have significance on citizens' perceptions of the bus fare conditions. When the residence of respondents is in the periphery zone, their perception is that bus is costly. As understood from the histogram of mode choice vs. zonal variations, the majority of bus users are living in the periphery area and their trip is characterized by a long travel time. Therefore, they have high transport expenses and regard bus as costly. Likewise, as age increases, so does the perception that bus is a costly mode of transportation. Male respondents think the bus is not a costly mode of transport, whereas females think the opposite. Since housewives are economically dependent on males, the transportation cost is likely more expensive for them so they are more likely to perceive the transportation cost as being expensive. Respondents who work do not perceive bus as costly. When monthly income increases, respondents feel that bus is not costly. However, increase in family size, bus fare, bus travel time, and bus waiting time make respondents perceive the bus as an expensive mode of transportation. The higher the number of bus connections or transfers, the more likely the bus would be more costly.

\section{Bus Convenience Model}

According to the ordered logit result of the convenience model, all the chosen factors (socioeconomic as well as mode attributes) have a significant effect (positive or negative) on citizens' perceptions of bus convenience, as the t-value is above the acceptable value. As age increases, the probability of perceiving bus service as inconvenient grows. It is the same for other attributes like monthly income, family size, number of bus transfers, bus travel time, and bus waiting time. The existing bus service is not convenient for elderly people because there are no priority seats or other policy incentives. A policy option that would provide suitable public transport service for the elderly is needed. Bus waiting time is also an indication of the need to improve bus stops and increase bus frequency. A longer travel time increases inconvenience, as there are chained trips. Male respondents and those who work perceive that the existing bus service is convenient because the bus is their preferable mode of transportation for their daily home-to-work trips. Most workers have too low of an income to afford another mode of transportation. Bus users think that bus service is convenient. As the bus fare increases, respondents 
suppose that the bus is convenient because for a long travel time the bus is a relatively affordable means of transportation.

\section{Bus Frequency Model}

Many of the attributes in the bus frequency model are not statistically significant because of the small t-value. However, all the results are presented in Table 3 to show the tendency of significance from the positive and negative signs of the coefficients. Four factors influence respondent's perceptions on the bus frequency: sex, number of bus connections, bus travel time, and bus waiting time. Since waiting time is explained by the frequency, it is not surprising that the $t$-value is a big value. Male respondents believe the bus is less frequent because of the longer waiting time they experience. Most females use buses for shopping purposes and not on a daily basis. When the number of bus transfer increases, respondents think the bus frequency condition is not good, where as an increase in in-bus time results in the perception of good bus frequency.

\section{Table 3. Ordered Logit Result for Bus Service Parameters}

\begin{tabular}{|c|c|c|c|c|c|c|}
\hline & \multicolumn{2}{|c|}{ Bus Fare Model } & \multicolumn{2}{|c|}{ Bus Convenience Model } & \multicolumn{2}{|c|}{ Bus Frequency Model } \\
\hline Independent variables & $\beta$ & t-ratio & $\beta$ & t-ratio & $\beta$ & t-ratio \\
\hline Constant & 2.1953 & 6.949 & 0.4879 & 1.535 & 2.1299 & 7.323 \\
\hline Mode & 0.4514 & 3.199 & 0.3781 & 2.751 & -0.1319 & -1.091 \\
\hline Zone & -0.2789 & -3.396 & -0.8679 & -9.69 & -0.1182 & -1.414 \\
\hline Age & -0.0060 & -1.624 & -0.0073 & -1.887 & -0.0045 & -1.294 \\
\hline Sex & 0.1098 & 1.920 & 0.1557 & 1.853 & -0.3036 & -3.026 \\
\hline Occupation & 0.1924 & 1.818 & 0.0787 & 2.692 & -0.0463 & -0.448 \\
\hline Monthly income & 0.0003 & 1.758 & -0.0001 & -1.891 & -0.0002 & -1.275 \\
\hline Family size & -0.0290 & -2.201 & -0.0260 & -1.680 & 0.0222 & 0.932 \\
\hline Waiting time & -0.0066 & -2.402 & -0.0095 & -1.669 & -0.0189 & -3.693 \\
\hline Travel time & -0.0097 & -2.497 & -0.0068 & -1.595 & -0.0062 & -1.687 \\
\hline Trip purpose & 0.0489 & 2.401 & -0.1331 & -1.896 & 0.0591 & 0.432 \\
\hline $\begin{array}{l}\text { Fare (differential of taxi and bus } \\
\text { fares for the specified distance) }\end{array}$ & -0.0002 & -2.112 & 0.0040 & 1.95 & -0.0024 & -1.236 \\
\hline No. of bus connections & -0.0723 & -1.595 & -0.0476 & -1.603 & -0.1854 & -4.316 \\
\hline \multicolumn{7}{|l|}{ Threshold values } \\
\hline$\mu(1)$ & 0.7841 & 6.509 & 1.4865 & 20.607 & 0.9571 & 15.628 \\
\hline$\mu(2)$ & 2.3551 & 17.464 & 2.7850 & 18.798 & 3.0252 & 25.955 \\
\hline No. of observations & & 674 & & 674 & & 674 \\
\hline Log likelihood function & & -631.5265 & & -611.8053 & & -707.1415 \\
\hline Restricted log likelihood & & -657.6018 & & -715.5172 & & -739.0919 \\
\hline Chi-squared & & 52.15059 & & 207.4238 & & 63.90071 \\
\hline Degrees of freedom & & 12 & & 12 & & 12 \\
\hline Significance level & & .05 & & .05 & & .05 \\
\hline
\end{tabular}




\section{Modeling Results: Binary Logit Model}

The estimated results of the public transport choice are given in Table 4. According to the logic result for choosing buses over taxi, all categories of the selected independent variables have a significant effect on choice. Periphery zone dwellers exhibit a high tendency for choosing bus over taxi because buses are an affordable means of transportation for long trips. In the innercity, trips tend to be short, so using a taxi could be seen as a reasonable option. However, for the urban poor living in the urban expansion area, buses are an indispensable choice because of the affordability issue. The probability of choosing bus decreases when age increases. This is due to the elderly tending to shift to other modes of transportation, as buses are crowded and are inconvenient to board. No policies or technical support exist to encourage the elderly to use the bus. Even the design of the high steps on the bus is not friendly to the elderly. Females tend to use buses more often than males, because females have spare time to wait for a bus as their destinations are not time restricted (predominantly shopping trips). Another significant factor is monthly income. When monthly income increases, the tendency of using a bus decreases (Figure 8). When residents' incomes increase, they look for a more convenient, although more costly, mode of transportation like taxi or private cars as the level of affordability has grown for them. Family size is another factor for bus choice. The larger the family, the higher the probability of choosing buses because other modes are unaffordable. Attributes related to mode also affect the

\section{Table 4. Binary Logit Result for Choosing Buses over Taxi}

\begin{tabular}{|l|r|r|}
\hline & \multicolumn{1}{|c|}{$\boldsymbol{\beta}$} & \multicolumn{1}{c|}{-ratio } \\
\hline Constant & -0.5162 & -2.6094 \\
\hline Zone: 0 if inner, 1 if intermediate, 2 if peripheral & 2.5439 & 9.1435 \\
\hline Age: Continuous value & -0.0210 & -1.9804 \\
\hline Sex: 1 if male, 0 if female & -0.1059 & -2.3663 \\
\hline Occupation: 1 if public and private company employee, and student; 0 otherwise & 0.4548 & 1.5819 \\
\hline Monthly income: Continuous value & -0.0023 & -6.4858 \\
\hline Family size: Continuous value & 0.0773 & 1.9901 \\
\hline Waiting time: Continuous value (differential of bus and taxi waiting time) & -0.1731 & -7.4338 \\
\hline Travel time: Continuous value & 0.0126 & 1.9204 \\
\hline Trip purpose: 1 if work, education, and business; 0 otherwise & 0.5966 & 1.4100 \\
\hline Fare: Continuous value (differential of taxi and bus fares for the specified distance) & -0.0032 & -1.6587 \\
\hline No. of bus transfers: Continuous value & -0.5733 & -4.2663 \\
\hline Dependent variable: Mode & & \\
Number of observations: 674 & & \\
Log likelihood function: -197.8537 & & \\
Restricted log likelihood: -348.3317 & & \\
Chi-squared: 300.9560 & & \\
Degrees of freedom: 11 & & \\
Significance level: 0.05 & & \\
Predicted outcome: $82.7 \%$ & & \\
\hline
\end{tabular}


probability of choosing a bus. When bus waiting time increases, there is higher probability for choosing a taxi. Therefore, bus frequency is the most important factor in determining residents' public transportation mode choice. Long travel time makes residents choose bus, as it is difficult to afford longer trips by taxi. The overall results showed that residents have a strong dependency on bus despite the low level of service. Besides, perception estimates impact mode choice.

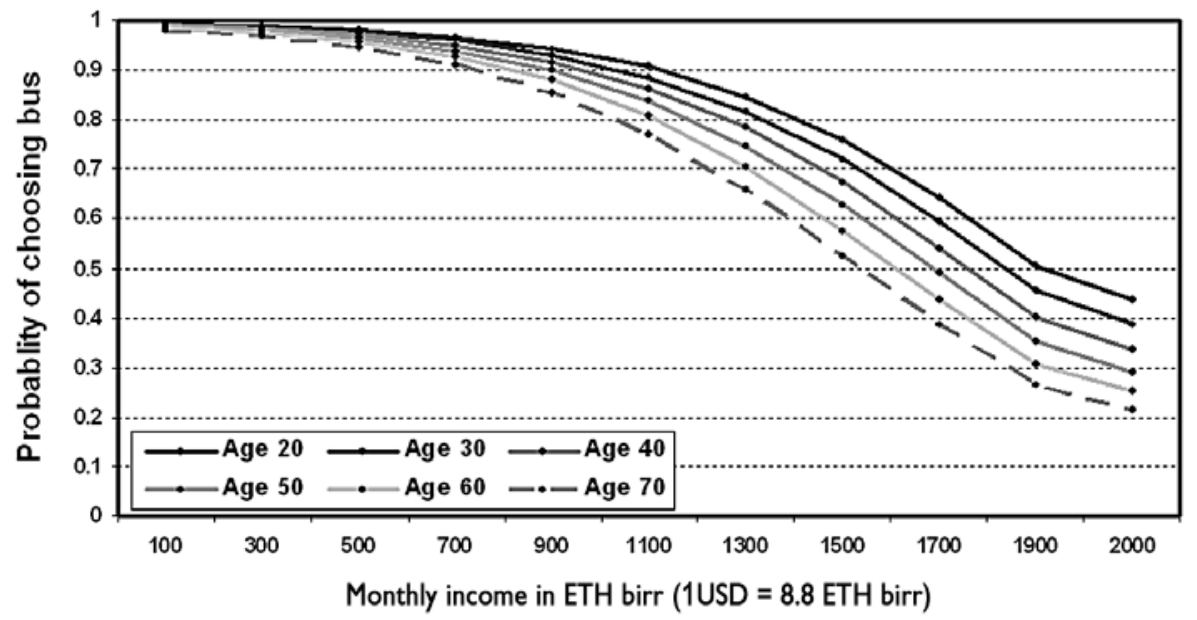

Figure 8. Probability of Bus Choice in Terms of Income and Age

\section{Discussion on Diagnostic Results}

In the previous sections, the factors that affect residents' choices of public transportation were analyzed by developing two probability models: the ordered logit model and the binary logit model. In addition, the relationship of independent variables in the two models is examined using a diagnostic approach as indicated in Table 5.

Periphery zone residents, who are public or private company employees with a larger family size, have a higher tendency of choosing bus over taxi. The positive sign with the distance variable is consistent with the choice of bus for long trips. Elderly people, male respondents, and residents with a higher monthly income are less likely to choose bus as their preferred public transportation mode. For the bus fare aspect, elderly females who are unemployed (or housewives), have a low monthly income, and have a large family size perceive the existing bus trans- 


\section{Table 5. Diagnostic Results of Mode Choice and Perception Models on Bus Condition}

\begin{tabular}{|c|c|c|c|c|}
\hline \multirow{2}{*}{ Parameters } & \multirow{2}{*}{$\begin{array}{l}\text { Binary Logit Model } \\
\text { (PT mode choice) }\end{array}$} & \multicolumn{3}{|c|}{ Ordered Logit Model (perception model on bus condition) } \\
\hline & & Cost (bus fare) & Convenient & Bus Frequency \\
\hline Zone & + & - & - & $\mathrm{NA}^{2}$ \\
\hline Age & - & - & - & NA \\
\hline Sex & - & + & + & - \\
\hline Occupation & + & + & + & NA \\
\hline Monthly income & - & + & - & NA \\
\hline Family size & + & - & - & $\mathrm{NA}$ \\
\hline Travel time & + & - & - & - \\
\hline Waiting time & - & - & - & - \\
\hline Trip purpose & + & + & - & + \\
\hline Fare & + & - & + & +1 \\
\hline \multicolumn{5}{|c|}{$\begin{array}{l}1+\text { and -signs show the independent variable's functional relation with the dependent variable. } \\
2 \text { NA: Parameters that are not applicable beca use they are statistically insignificant (very low t-value). }\end{array}$} \\
\hline $\begin{array}{l}\text { Socioeconomic } \\
\text { Parameters }\end{array}$ & \multicolumn{4}{|l|}{ Diagnosis } \\
\hline Place of residence & \multicolumn{4}{|c|}{$\begin{array}{l}\text { Periphery area residents choose bus because their trips are longer than inner zone residents' } \\
\text { trips. They perceive that bus is a costly and inconvenient mode of transportation. }\end{array}$} \\
\hline Gender issue & \multicolumn{4}{|c|}{$\begin{array}{l}\text { Male respondents do not choose bus despite bus being an affordable means of transportation fo } \\
\text { their daily work trip. They perceive low bus frequency as decreasing their probability of choosing } \\
\text { bus. }\end{array}$} \\
\hline Age & \multicolumn{4}{|c|}{$\begin{array}{l}\text { Elderly do not choose bus because of crowding and boarding inconveniences. Their attitude } \\
\text { toward bus fare as well as its convenience shows that they are not satisfied with the existing bus } \\
\text { service. }\end{array}$} \\
\hline $\begin{array}{l}\text { Income vs. public } \\
\text { transportation fare }\end{array}$ & \multicolumn{4}{|c|}{$\begin{array}{l}\text { Low-income groups choose bus because it is a cheaper mode of transportation. As taxi fare } \\
\text { increases (longer trips), the probability of choosing bus increases. High-income groups think tha } \\
\text { bus is not convenient and has very low frequency. They do not choose bus because they can } \\
\text { afford taxi and/or private car. }\end{array}$} \\
\hline Family size & \multicolumn{4}{|c|}{$\begin{array}{l}\text { Families of a larger size choose bus yet they consider bus a costly and inconvenient mode of } \\
\text { transport. Affordability is a question as the family size increases. }\end{array}$} \\
\hline Bus users & \multicolumn{4}{|c|}{ Bus users perceive that bus is not costly. However, they think that bus has very low frequency. } \\
\hline $\begin{array}{l}\text { Origin-destination } \\
\text { distance }\end{array}$ & \multicolumn{4}{|c|}{$\begin{array}{l}\text { The longer the trip distances, the higher the probability of choosing bus. Bus is the preferable } \\
\text { mode of transportation for long trips. }\end{array}$} \\
\hline Waiting time & \multicolumn{4}{|c|}{$\begin{array}{l}\text { High waiting time reduces the probability of choosing bus. The probability of perceiving bus as a } \\
\text { costly and inconvenient mode increases with an increase of the waiting time. }\end{array}$} \\
\hline Chained trips & \multicolumn{4}{|c|}{$\begin{array}{l}\text { When the number of bus transfers increases, bus is perceived as a costly, inconvenient, and } \\
\text { nonfrequent mode of transportation. }\end{array}$} \\
\hline
\end{tabular}

portation as costly. When the convenience aspect is considered, the same group perceives bus as an inconvenient mode of public transport except for the monthly income parameter. Those who have a higher monthly income perceive bus as an inconvenient mode of public transportation. In addition, the longer distances, shorter waiting times, and cheaper bus prices increase the probability of choosing bus and enhance the perception of bus convenience. Low bus frequency (long waiting time) and high fares increase the probability of perceiving bus as a costly 
and inconvenient mode of public transport. The ordered model results show that periphery residents are not satisfied with the bus condition. Even if bus is the affordable means of transportation, it is still difficult for the urban poor living in the urban expansion area to afford. One of the reasons they perceive bus as a costly mode is the very limited bus networks in the periphery area, thus forcing them to pay for a more expensive mode of transportation like a taxi. Bus service is not convenient for periphery residents, as there is longer travel time and very low bus service coverage (Figures 9 and 10). According to the results of the ordered logit model, the number of bus transfers is one of the independent parameters that influences residents' perceptions on bus condition. The number of bus transfers has a negative sign for the three dependent variable parameters. This shows that residents are not satisfied with the bus linkages.

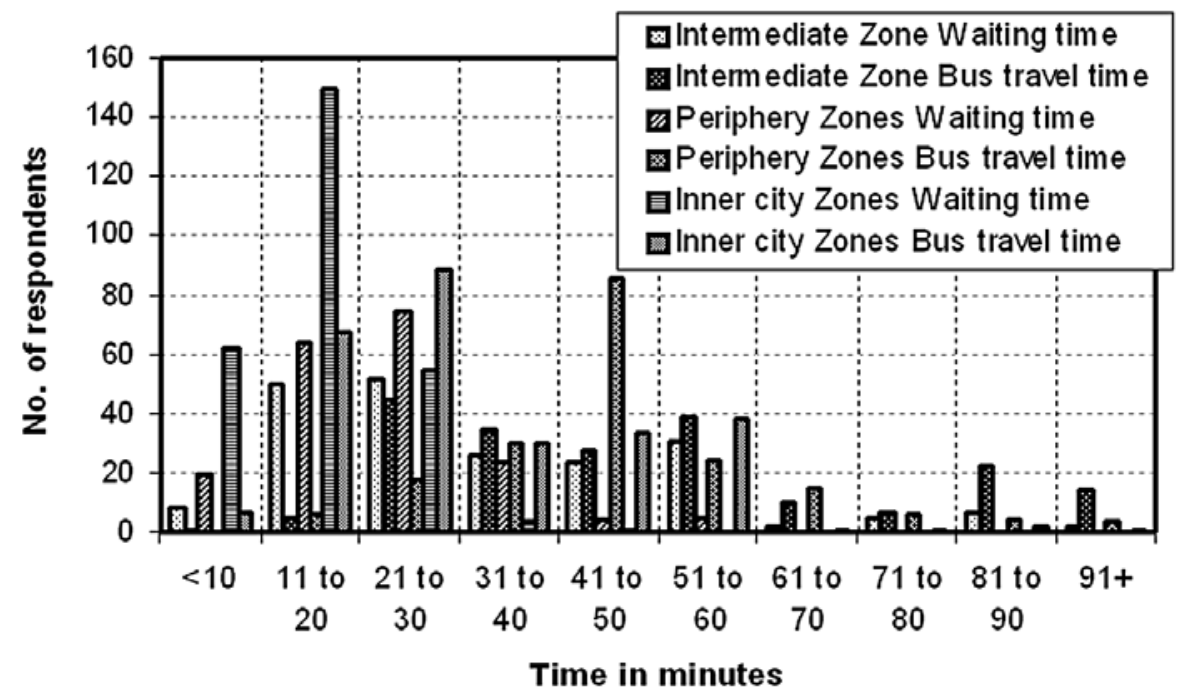

Figure 9. Bus Waiting and Travel Time in Different Zones 

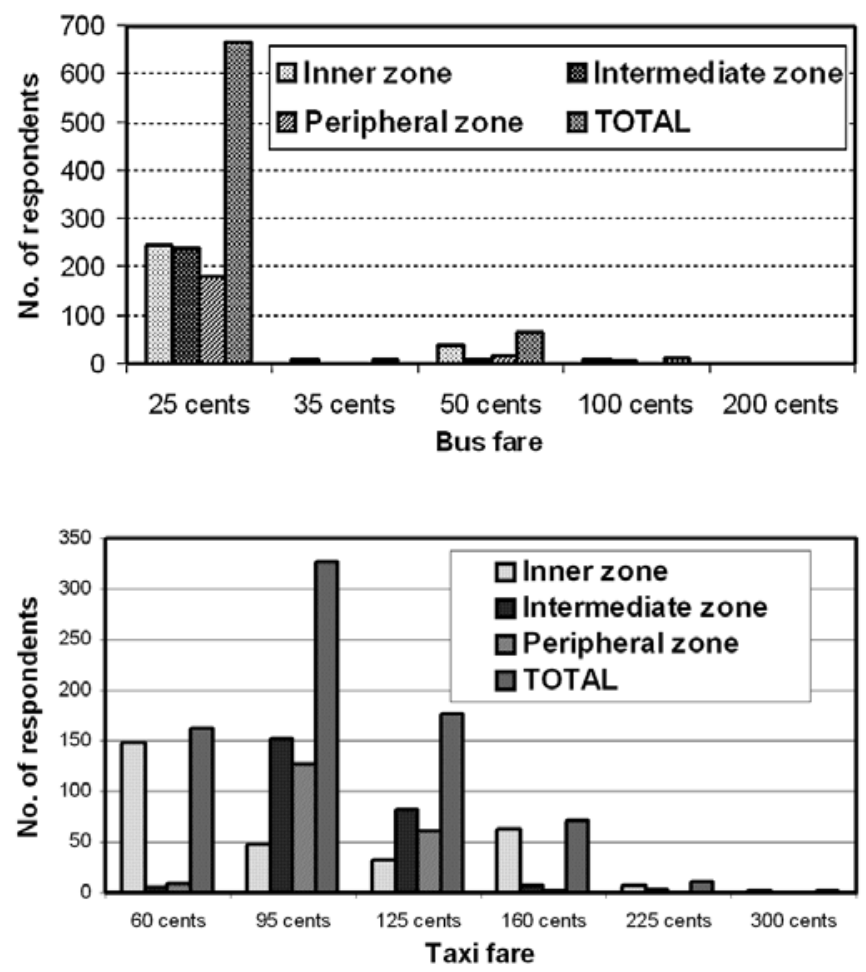

\section{Figure 10. The Relationship Between Public Transportation Fare and Zones}

\section{Conclusions}

This study presents a diagnostic analysis of the existing public transport situation in Addis Ababa. A binary logit model was assessed for the public transportation mode choice analysis; and an ordered logit model is implemented to analyze the ranking responses of citizens' perceptions on the condition of the current bus service. In addition to the widely used mode choice model, the newly developed ordered logit model result is useful to make a further analysis of the bus condition aspects influencing bus transportation choices. In a situation with limited alternatives, such an approach would explain better the respondents' choice characteristics.

The analysis results showed that socioeconomic as well as public transport moderelated parameters have a significant negative or positive influence on the mode 
choice and the respondents' perceptions of the bus service condition. Based on the results and further analysis and considerations, the strategic plan, policy indications, and physical solutions could be drawn as an effort to improve the existing public transport services. Spatial expansion of bus service, improving bus frequency conditions, and strengthening the bus linkage with respect to the land use are among the policy intervention areas.

\section{References}

Anbessa City Bus Enterprise. 2004. 2004-2005 yearly report, Addis Ababa (written in Amharic).

Darido, Georges B. 2003. Regulation of road-based public transportation and strategies for the developing world. Transportation Research Record 1835, TRB National Research Council, Washington DC, pp. 66-73.

Ethiopian Roads Authority (ERA). 2005. Urban transport study and preparation of pilot project for Addis Ababa. Consulting Engineering Services (India) Private Limited and SABA Engineering Private Limited Company, Addis Ababa, Ethiopia.

Ghareib, Ahmed Hamdy. 1996. Evaluation of logit and probit models in modechoice situation. Journal of Transportation Engineering 122, 4: 282-290.

Greene, William H. 1998. LIMDEP version 7.0 users manual. Econometric Software, Inc.

Greene, William H. 2000. Econometric analysis, 4th ed. Prentice-Hall, Inc.

Hamed, Mohammad M., and Said M. Easa. 1998. Ordered probability modeling of seat belt usage. Journal of Transportation Engineering 124, 3.

Jacobs, G. D., D.A.C., Maunder, and P.R. Fouracre. 1986. Characteristics of conventional public transport services in third world cities. Traffic Engineering and Control 27, 12: 6-11.

Mintesnot, G., and S. Takano. 2005a. Modeling the relationship between seasonal constraints and modal choice characteristics of high school students in snowy regions. Journal of Eastern Asia Society of Transportation Studies 6: 1844-1857. 
Mintesnot, G., and S. Takano. 2005b. Citizen's attitude, existing challenges and prospects of bus transportation in the city of Addis Ababa, Ethiopia. Proceedings of Japanese Society of Civil Engineers 60.

Mintesnot, G., and S. Takano. 2006. Application of logical planning model for public transportation improvement programs in the city of Addis Ababa. Studies in Regional Science. Journal of JSRSAI 36: 663-682.

Office of the Revision of Addis Ababa Master Plan (ORAAMP). 2002. Project proposal for Addis Ababa transport sector, Addis Ababa, Ethiopia.

Racca, David P., and Edward C. Ratledge. 2004. Project Report for "Factors That Affect and/or Can Alter Mode Choice." Delaware Transport Institute and State of Delaware Department of Transport.

SEMALY Public Transport Consultants. 2001. Comments about prospective mass transport system in Addis Ababa City, Addis Ababa, Ethiopia.

Thamizh Arasan, V., V. R. Rangaraju, and K. V. Krishna Rao. 1996. Trip characteristics of travelers without vehicles. Journal of Transportation Engineering 122, 1: 76-81

Wang, Xiaokun, and Kara M. Kockelman. 2005. Occupant injury severity using a hetroscedastic ordered logit model: Distinguishing the effects of vehicle weight and type. Transportation Research Board Annual Conference, Washington DC.

World Bank African Region Scoping Study. 2002. Urban mobility in three cities, Addis Ababa, Dar es Salam, Nairobi. SSATP Working Paper 70.

Yamamoto, Toshiyuki, Satoshi Fujii, Ryuichi Kitamura, and Hiroshi Yoshida. 2000. Analysis of time allocation, departure time, and route choice behavior under congestion pricing. Journal of Transport Research Board 1725: 95-101.

\section{About the Authors}

Mintesnot GebeyehU (mintesnot@gmail.com) is a Ph.D. student at Hokkaido University, Department of Urban and Environmental Engineering. He holds a master's degree in urban engineering and planning from Hokkaido University. His research focuses on urban land-use planning and public transportation planning and policy. 
SHIN-EI TAKANO (shey@eng.hokudai.ac.jp) is an associate professor of transportation planning and construction management at Hokkaido University, Department of Urban and Environmental Engineering. His research focuses on public transportation planning, construction management, and tourism transport management. He has participated in many national and local transportation projects and has reviewed several research papers for refereed journals. 